\title{
FRAMEWORK TO IMPLEMENT COLLABORATIVE ROBOTS IN MANUAL ASSEMbly: A LEAn Automation APPROACH
}

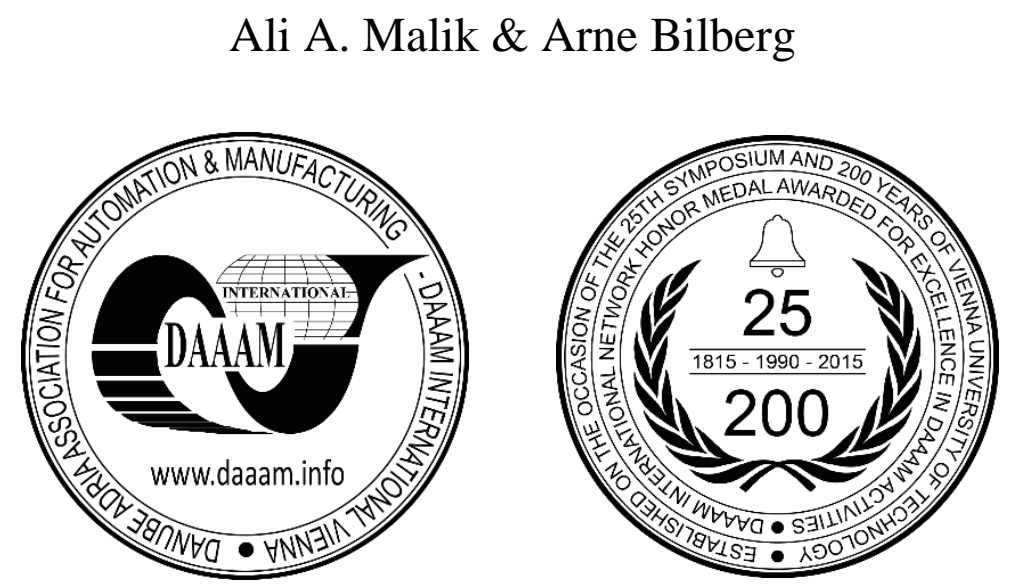

This Publication has to be referred as: Malik, A[li] A[hmad] \& Bilberg, A[rne] (2017). Framework to Implement Collaborative Robots In Manual Assembly: A Lean Automation Approach, Proceedings of the 28th DAAAM International Symposium, pp.1151-1160, B. Katalinic (Ed.), Published by DAAAM International, ISBN 978-3-90273411-2, ISSN 1726-9679, Vienna, Austria

DOI: $10.2507 / 28$ th.daaam.proceedings.160

\begin{abstract}
The recent proliferation of smart manufacturing technologies has emerged the concept of hybrid automation for assembly systems utilizing the best of humans and robots in a combination. Based on the ability to work alongside human-workers the next generation of industrial robots (or robotics 2.0) are referred to as collaborative robots or cobots. This paper presents a systematic framework based on Roozenburg's engineering design cycle for the deployment of cobots in existing assembly cells for enhanced productivity. A model for defining evaluation-parameters for a cobot are presented. The effectiveness of virtual simulations is discussed for validation and optimization of human-robot work environment.
\end{abstract}

Keywords: Cobot; framework; collaborative; assembly system; cobot selection; HMLV; Lean automation; HRC

\section{Introduction}

The increasing demand of customization and shortened product life-cycles are pushing manufacturers to develop variant-oriented production systems [1]. The production paradigms are changing towards increasing flexibility and responsiveness of production processes, facilities, and networks. The same production system is expected to adapt to frequent changes in products, components and tasks [2]. Whereas the classical assembly methods for high-mix lowvolume (HMLV) production are incompatible with the increasingly globalized industry. It is well agreed in the research literature that the flexibility and changeability are key elements to deal with the challenges of a global market [3] [4].

Besides high wage rates in Northern Europe, humans are responsible for $90 \%$ of the production tasks in final assembly [5]. Fasth [4] described the high degree of intelligence required in the assembly process as a challenge for automation of the final assembly systems and humans having a higher degree of intelligence are more suited for such intelligent tasks. Thus, the mainstream automation has always been far from combining the human and artificial resources. In conventional automated production systems, humans' tasks are designed to be as rigid as the rest of the automation [2] and it, thereby, keeps the humans and robots away from each other. In the last half century, industrial robots have assisted in huge productivity improvements but they remained in caged environments, away from any physical interaction with humans. 
In the new industrial robotics paradigm (or robotics 2.0) robots are not fenced in cages but they are expected to become a fellow of humans in their work environment. Various researches have been made to realize the complementary strengths of humans and robots and combine them for collaborative work. Based on the paradigm," factories are long-life and complex products", this research uses product design theory to design and develop a human-robot collaborative production system. In this research paper a structured procedure is developed by analyzing the business needs, evaluating the requirements, fusing the infrastructural elements and translate this into a functional human-robot collaborative (HRC) solution.

\section{What is Cobot?}

The concept of a Collaborative Robot was first presented by Colgate [6] as an Intelligent Assist Device (IAD) which manipulates objects in direct collaboration with a human operator. The unique characteristic of cobots are their direct interaction with human operators, shared control of motion and provision of virtual surfaces to constrain and guide worker's motion (see Fig. 1). The resulted benefits are expected as enhanced productivity, better ergonomics and improved safety [7][8]. Kruger [28] described cobot as a mechanical device for human-machine cooperation in assembly lines through direct physical contact. The cobots being developed today are articulated with multiple rotational joints developing a high degree of flexibility and dexterity to reach every coordinate of their workspace in multiple configurations [9]. These cobots provide guidance while human operator offers motive power, flexibility and intelligence to complete a task. Cobots are designed to have direct interaction with fellow humans as well as with other robots and share the workload considering the abilities and strengths of each team member. The possible advantages are expected in productivity and improved ergonomics [5].

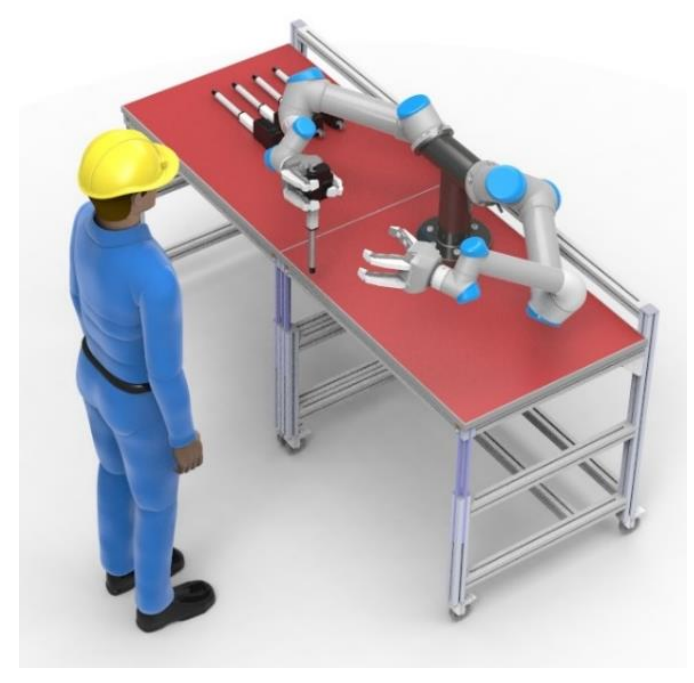

Fig. 1. A two-arm collaborative robot (Cobot)

\section{Cobot as an enabler of lean automation in assembly cells}

Production in high-wage economies demands a high degree of automation. A general limitation of mainstream automation is that it addresses low-mix high-volume production. The relationship between production volume, flexibility, automation and product variety is shown in (see Fig. 2). Heilala [10] had also presented a similar relationship between flexibility, volume, variants and batch size. Due to the need of variability in assembly-tasks, final assembly systems are designed to be manual systems. Hence the most flexible elements in an industrial assembly system are the humans. The natural intelligence of humans enables them to easily adapt to production changes and requirements [11]. To enhance the productivity of the production systems, in the last few decades, Lean Production principles gained popularity that promise a continuous improvement by avoiding the waste and focus on the value adding activities [12]. Already in 1990 approaches were presented to combine lean production principles into automation technologies resulting in non-complex and less over engineered automation solutions. Dulchlnos [13] defined lean automation as, "Lean automation is a technique which applies the right amount of automation to a given task. It stresses robust, reliable components and minimizes overly complicated solutions". With the emerge of Industry 4.0 concepts an increasing trend is being observed to incorporate robotics and automation in increasingly more fields of human activity in industrial assembly processes [14]. The human-robot integrated production systems combine the creativity, intelligence, knowledge, flexibility and skill of humans with the electronics and physical power, speed and accuracy of a machine. The approach enables an assembly system to produce complex on-demand products at reduced costs [15]. 


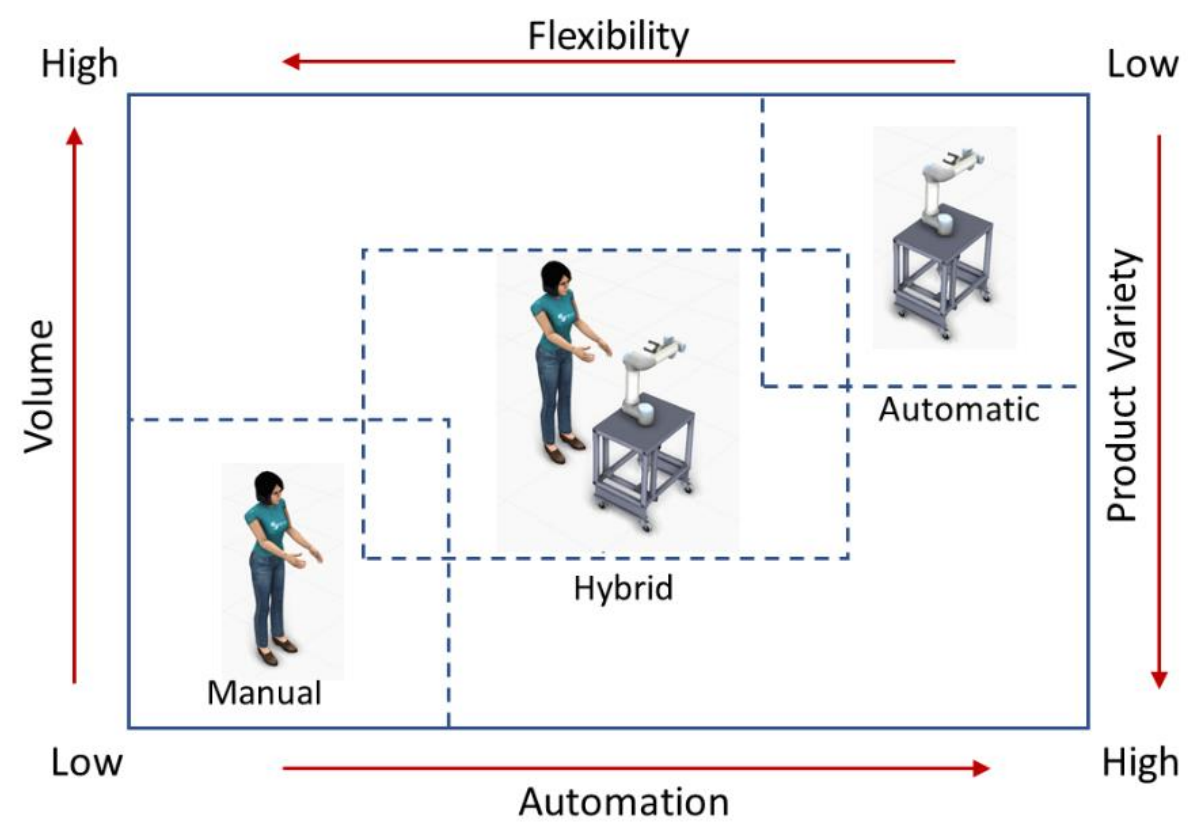

Fig. 2. Flexibility and automation (Modified from Heilala [10] and Rosati [31])

\section{Factory as a product}

Westkamper presented the paradigm, "factory is a long life and complex product". The basis of this paradigm is the argument that, from a system theory perspective, manufacturing systems can be modelled as complex technical systems [16]. Later, many researchers have used product-design-theories for manufacturing-system-design, thus strengthening the

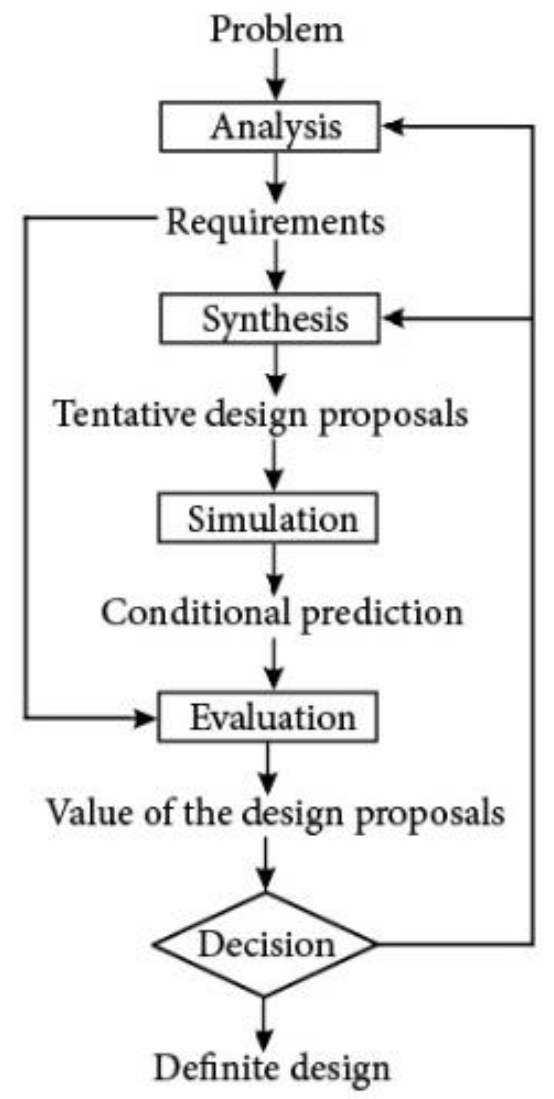

Fig. 3. Engineering design cycle by Roozenburg [18] 
paradigm of "factories-are-products". Wiendahl [17] further described the process of planning a production system as a systematic, goal-oriented, and structured design process that supports activities from the first idea to the start of production. In this regard, Roozenburg's engineering design cycle [ eekels1991methodological ] is an iterative systematic approach to design technical systems as products (see Fig. 3).

The product design structure, as suggested by Roozenburg, is a sequence of empirical activities, in which a solution is achieved by cyclic progression in knowledge of the problem as well as of the solution. The process starts with identification of the problem and gradually reaches to the stage where a definite design is achieved. In a later research Francalanza [16] used the engineering product design cycle by Roozenburg and derived a systematic approach to design changeable manufacturing systems.

\section{A systematic framework for cobot deployment in assembly cells}

Based on above research works, this paper derives a systematic approach to implement cobots in an assembly system and enlists associated activities in developing a hybrid assembly work-cell (see Fig. 4). This process is divided into three phases of concept development phase, exploration phase and decision phase. The concept phase involves analyzing the business needs and production process, thus defining the needs and requirements for a hybrid assembly system.

Exploration phase highlights the activities of defining the requirements for the functional elements (e.g. cobot and worker) of the production system, layout design and designing the interaction structure of these functional elements. Decision phase involves concluding a provisional design, developing virtual prototypes of the design and achieving a final design. Each phase has an analysis component to analyze and optimize the design and make it aligned with the previous design stages. The design components within each of the three phases are described below:

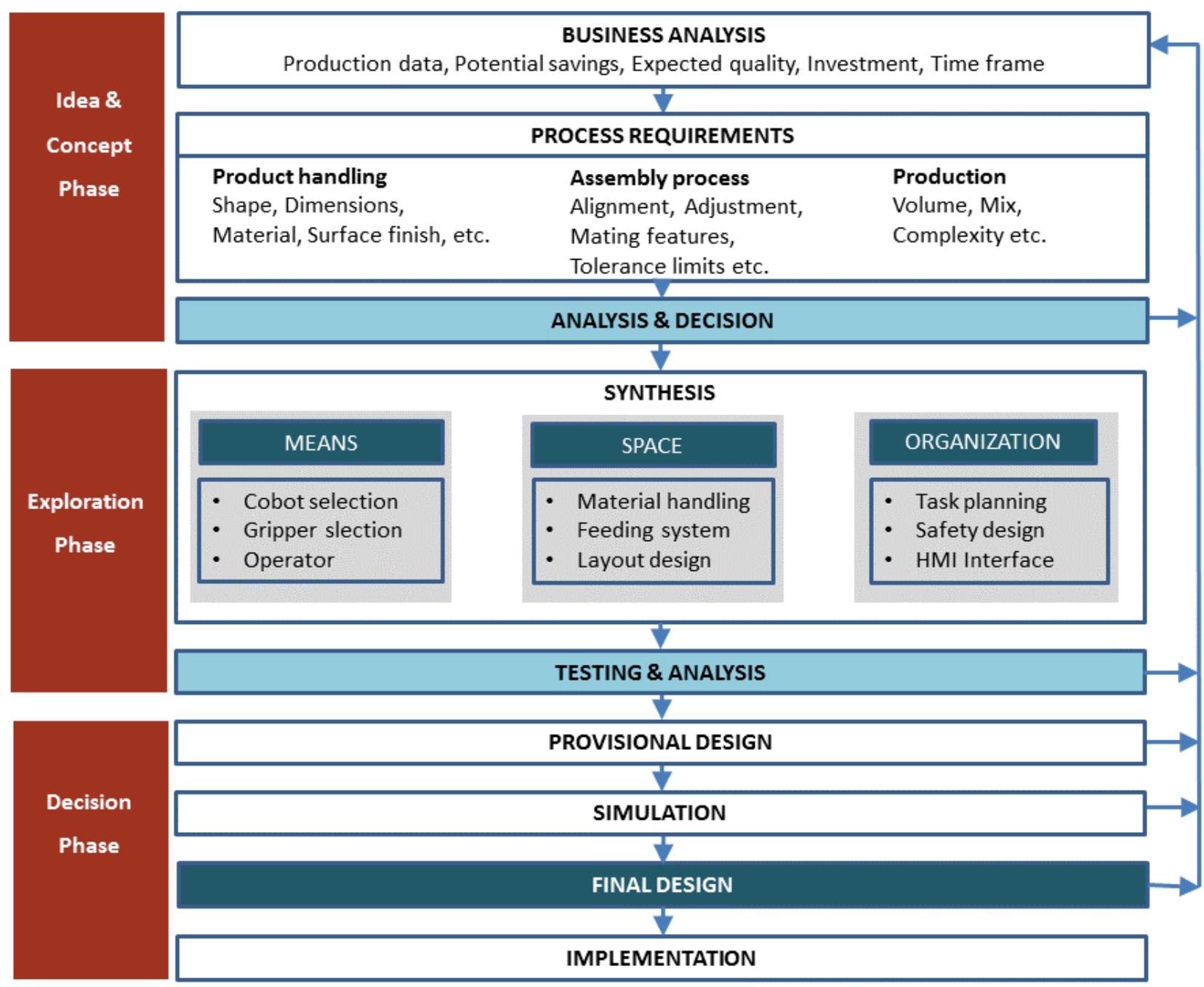

Fig. 4. Systematic framework for cobot implementation 


\subsection{Problem and requirements}

Innovative factory planning processes emerge from the business strategy of an enterprise [19]. Hence investigating the associated potential business gains are the first step towards a new production strategy. This step is a product of the Investment and Performance Planning stage and defines the goals and targets to be achieved with hybrid flexible assembly automation. e.g. 'Cost per part', 'investment cost', etc. [16].

\subsection{Requirements of the hybrid production system}

The next stage in the process of implementing cobot to develop a human-robot collaborative assembly system is the analysis of the assembly-process. This includes analysis of the product design and assembly sequence for which cobot is being proposed for hybrid lean automation. Chryssolouris [20] stated the basic goal of a production system is to produce the required products at a required time, cost, quality and flexibility. Hence, the requirements of a human-robot automation may fall within the categories of product handling requirements, process requirements and production requirements:

- Product handling requirements: define the physical properties of the parts and components that make-up as product(s). It is required to analyze the properties (e.g. form, shape, dimensions, tolerances, material, weight, size and surface finish etc.) of the parts and components to be handled by the cobot during the assembly process.

- Process and insertion requirements: The sequences of the assembly process, alignment of parts, angle of rotation, mating features and fastening methods need to be investigated. This also includes need of fixturing and testing of subassemblies [21].

- Production requirements: These are the requirements for required production volume, cycle time, variety in the product (s) and associated complexity of the process.

\subsection{Analysis of the concept phase}

The above three types of assembly requirements within the categories of product, process and production, adds to the complexity of the assembly process for automation. A possible solution is to make structured complexity assessment based on above data for automation. Many researchers have attempted to define the manufacturing complexity and methods to quantify it.

The complexity assessment work by ElMaraghy is of significance to quantify manufacturing operational complexity [22], products assembly complexity [23] and complexity of an assembly system [24]. However, it is proposed that a more comprehensive complexity model for the objective of hybrid-automation be developed that comprehends all above important parameters of an assembly process. These analyses will also define the set of criteria for evaluation of the hybrid assembly system to be developed at the later stage.

\subsection{Synthesis}

Synthesis is described as an activity of mixing ideas, influences and/or things to form a connected whole. This is the stage where manufacturing designers form solutions for a collaborative flexible manufacturing system. A production system is "a place of adding value by production with the help of production factors" [17]. It is a complex socio-technical system that consists of elements and objects.

For the purpose of defining factory objects Nyhuis [25], classified the factory objects as means, space and organization and placed them at four different levels of station, system, segment and site levels. However, this research will focus only on the technical requirements at the station level. The means, organization and space in this classification refer to production equipment, operational structure and workspace design respectively [25].

\subsubsection{Means}

Means of production at the station-level define the production equipment and resources. In the case of a hybrid humanrobot work system, the production equipment is cobot, cobot-grippers and worker. 


\section{a. Selection of cobot}

There are several commercially available cobots with varying capabilities and strengths. It is critical to decide a cobot that best suits to the needs of the assembly system. Many researchers have presented the evaluation and selection of an industrial robot as a multiple criteria decision making (MCDM) problem. Chatterjee [26] classified the attributes or properties of an industrial robots as objective (numerically defined e.g. load, cost etc.), subjective (qualitative in nature e.g. programming flexibility, vendor's service quality etc.), beneficial (whose higher values are desirable e.g. load carrying capacity) and non-beneficial attributes (whose lower values are desirable e.g. cost, repeatability etc.) [26]. Multiple studies are made to achieve the objective of scoring and evaluating the selection parameters through various scientific analysis e.g. mathematical, statistical, simulations etc. Finally, the scores are normalized to same-units to help make a comparison. Mortensen [27] presented a literature review of 19 scientific studies for robot evaluation that enlists the set of parameters used and the evaluation method. However, the determination of selection-criteria in robot selection process is an overlooked issue in the research literature [27]. Additionally, the parameters discussed so far by researchers are associated with the basic functionality of a robotic manipulator and are not considering the fact that a cobot, as a hybrid-automation tool, needs additional parameters for its performance evaluation e.g. safety, social interaction, and ease of use. The "Domain Theory" by Andersen [28] suggests that multiple perspectives are associated with any product structure. Based on this theory, a multi-perspective view is presented for determining an evaluation criteria for a cobot (see Fig. 5). These parameters are:

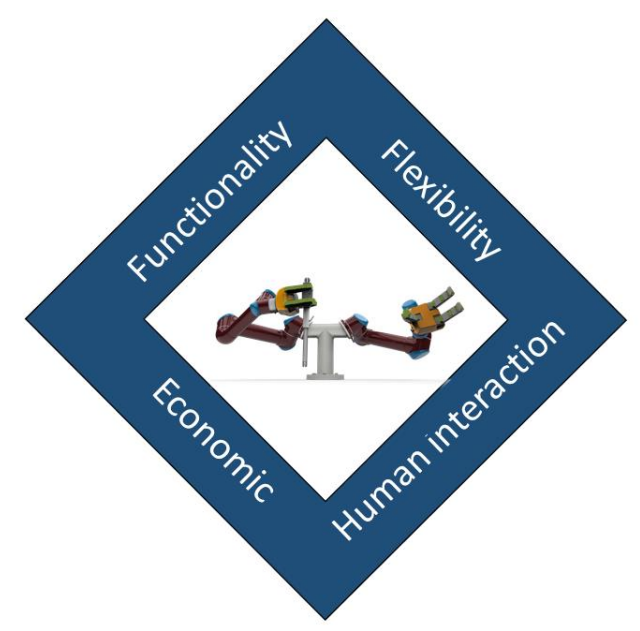

Fig. 5. Different views to define cobot selection-parameters

- Functional view: describes the properties that help the cobot to perform its basic functionalities i.e. payload, degrees of freedom, accuracy, repeatability etc.

- Human-interaction view: The elements that define the ease and suitability for human interaction of a cobot e.g. ease of programming.

- Flexibility view: A cobot is supposed to ensure flexibility to realize transformation of the production scenarios. For this, it must carry specific characteristics referred to as change enablers. Wiendahl [17] described change enablers as specific characteristics that can be activated at a specific time to create a design change e.g. modular design of cobot to various reach and payload conditions.

- Economic view: These elements are defining the investment related aspects of a cobot.

\section{b. Selection of gripper}

Since the targeted objective of building a human-robot collaboration is to have a fine balance between flexibility and productivity, therefore the material feeding systems must exhibit high flexible [29]. However, the technology to develop flexible grippers that can adapt to several shapes, sizes and material conditions is still developing. Kruger [29] has presented a spectrum of gripping systems based on flexibility of a gripper and costs. The spectrum consists of two extremes positions. At one end, it has a cost effective two fingers gripper with lower flexibility and on the other end is a complex hand-like gripper with several DoF but the price can exceed the price of a robot system (see Fig. 6). 


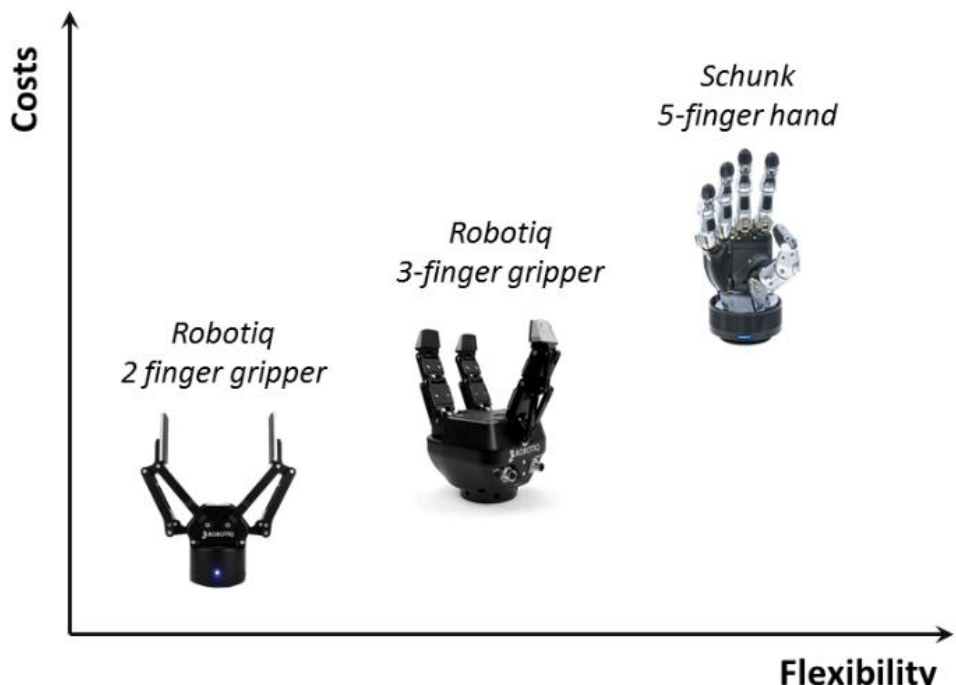

Fig. 6. Spectrum of robotic gripping systems [29]

\section{c. Training need assessment for human-worker}

Human-operator is at the heart of a lean automation system [30]. The production design elements for human operator are related to skill requirements analysis and training. In a robot-collaborative production system, the operator needs to have certain skills to interact with the robot. The operators may also face social challenges while working with robotics. A training assessment is developed to train the operator to work alongside robots.

\subsubsection{The workspace}

The elements of workspace design are material handling system, feeding system and layout design. For a flexible assembly system, a big challenge lies in the flexible feeding of parts and components into the assembly process. Mainstream automation in this area is quite rigid and deals with specialized feeder for each type of parts [29]. While presenting fully flexible assembly systems Rosati [31] presented flexible feeding of parts into an assembly operation with vision systems. An approach for flexible automated material handling can be automated guided vehicles (AGV). AGVs are being used in industries since many years but now they are getting smarter and flexible with low cost advanced electronics and autonomous navigation systems [29]. Modern assistive collaborative robots are another possible form of flexible material handling in smart workplaces [32] (see Fig. 7).

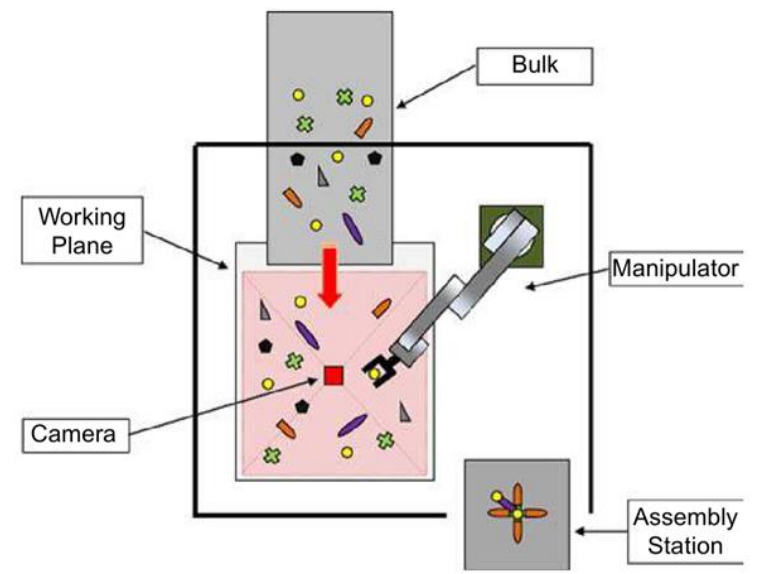

a)

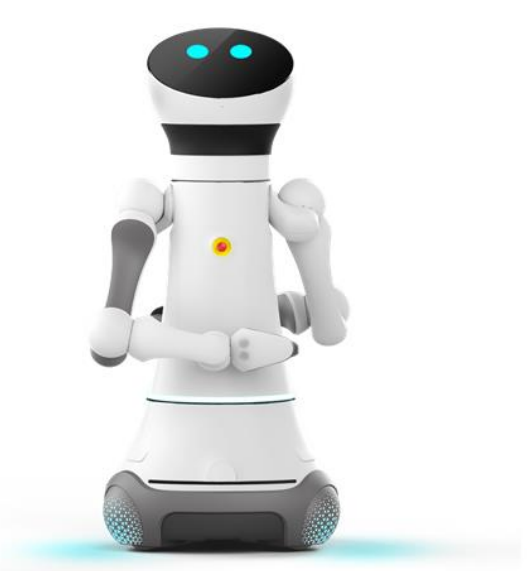

b)

Fig. 7. (a) Vision based flexible material feeding [31] (b) Care-o-bot for flexible material handling [32] 


\subsubsection{Organization of the production elements in the workspace}

The interface between operator and cobot consists of activities that make the manufacturing system collaborative. These include effective distribution of tasks, safety system design, and human-machine interface (HMI). HMI is important for instructing the robot and making changes to an existing program of the robot. Furthermore, in a factory environment, the question of task-allocation arises when both, human and robot, can perform the same task [33]. The major challenge is the lean-distribution of tasks relying on the best attributes of robots and humans in a combination. Careful planning is needed to design an optimal workstation. In a common observation, the designers automate everything possible and leave the rest to be performed by the human [4]. A modified form of task distribution presented in [29] is shown in Fig. 8. The research realizes that safety design is a comprehensive area of work when developing an HRC solution. There are various industrial standards that define the safety requirements of an industrial machine or robot. These standards are also being modified to the needs of HRC workplaces. However, considering the wide scope of safety design this research remains away from describing any details of the safety system design for HRC.

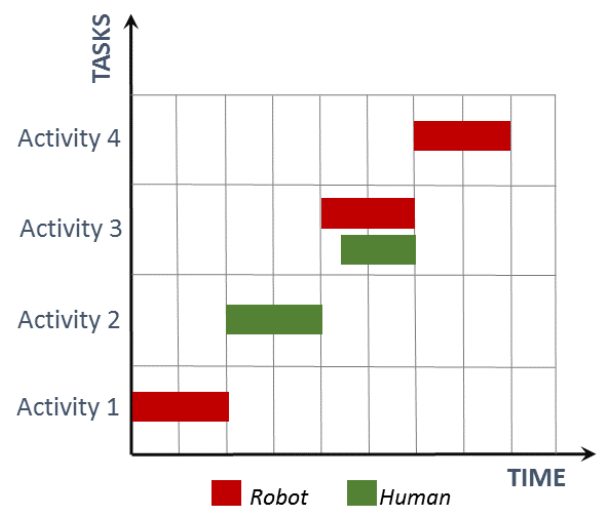

Fig. 8. The distribution of tasks between human and robot

\subsection{Virtual simulation for testing and validation of the production system}

Simulation phase involves construction of simulation models, test alternatives, optimize solutions, deducing hypothetical observations and predictions out of it before implementation in the real world. The accuracy of the simulation model is highly important to make observations as correct as possible. Though the results will not satisfy all but can help investigate most of the aspects of the proposed solution. A major advantage of having digital prototype of a production system offers the possibility to experiment a range of scenarios every time a parameter is changed. The results are concluded as a reduction in the overall production-system development time and cost [34]. Several virtual production simulation tools are available of which discrete event simulation (DES) are most popular in production environments.

A major challenge towards designing an HRC production system is the activity and task planning between human and robot. The times to complete each task are highly important to be calculated to design an optimal balance between the two means of production. Simulations can also prove to be a helpful tool in quantifying the processing times for both the operator and the robot. There is a limited availability of HRC simulations both in commercially available software and published research. Additionally, HRC simulations can play a vital role in safety assessment of human-robotic work cells. Simulators that can integrate physical phenomena of HRC can make great impact to safe HRC design [35]. The results will further translate into designing the optimal workstation layout. Backman [9] used simulation software, Industrial Path Solutions (IPS) from the Fraunhofer - Chalmers Center and Intelligently Moving Manikins (IMMA) developed by Dassault Systems to simulate robot and the human in an isolated simulation environment and the results were implemented for a cobot-human production system.

In this research DES software Tecnomatix Process Simulate by Siemens is used for design and validation of the human-robot automation. Tecnomatix provides an HRC environment for combined simulation of robot and operator.

The simulation helped to:

- Assess the cycle times for each activity of the assembly process

- Make reach tests for both cobot and the operator thus helping in the layout design of the assembly station

- Use the robot simulation for offline programming and transfer the code to a physical robot 
The results from the simulation are then evaluated against the criteria defined at the analysis and requirements phase. It is then quantified to examine how well this satisfies the evaluations/ requirements criteria.

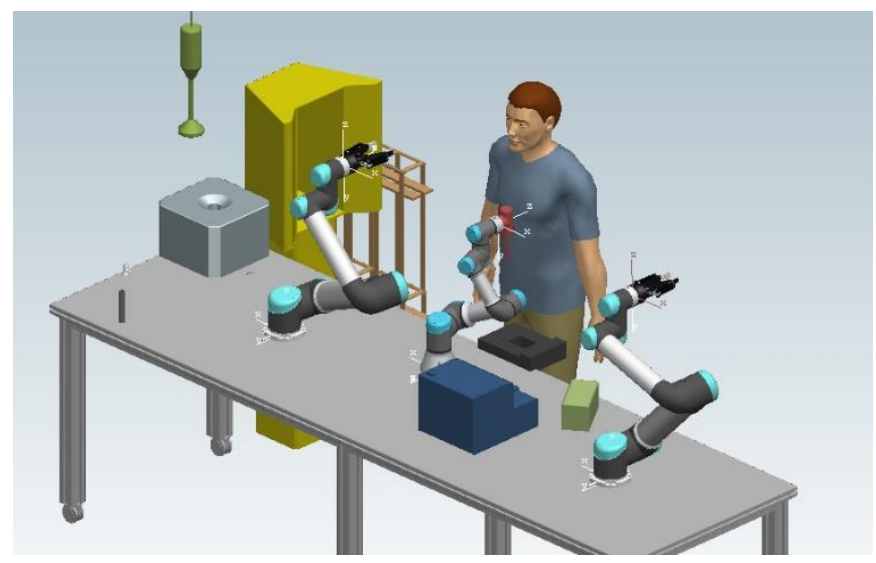

Fig. 9. Simulation of human and robot in Tecnomatix Process Simulate

\subsection{Final design}

The decision phase will conclude a design of the production system from all the previous analysis. It will also involve comparing the results with the requirements and criteria defined in the concept phase. This will help to determine whether the design is feasible enough to be moved to the implementation phase or if it needs modifications.

\section{Conclusion}

The research identifies cobots for lean-automation and strengths based distribution of tasks between robot and human in a common work environment. In the form of a systematic framework a mapping of activities is presented for implementation of cobots in assembly cells. It is proposed that a comprehensive generalized task-distribution methodology is developed considering the various attributes of an assembly process. The cobot evaluation model is presented that is not only helpful for manufacturing companies to evaluate market available cobots but also can help cobot-developers to define cobot specifications considering the future needs of manufacturing companies.

\section{References}

[1] Park, H. (2013). From automation to autonomy - a new trend for smart manufacturing, Chapter 03 in DAAAM International Scientific Book 2013, pp. 075-110, B. Katalinic \& Z. Tekic (Eds.), Published by DAAAM International, ISBN 978-3-901509-94-0, ISSN 1726-9687, Vienna, Austria.

[2] Wang, X.V.; Kemény, Z.; Váncza, J. \& Wang, L. (2017). Human-robot collaborative assembly in cyber-physical production: Classification framework and implementation, CIRP Annals-Manufacturing Technology.

[3] Mulc, T.; Udiljak, T. \& Ciglar, D. (2015). Structure of reconfigurable manufacturing systems, Chapter 32 in DAAAM International Scientific Book 2015, pp.369-390, B. Katalinic (Ed.), Published by DAAAM International, ISBN 978-3-902734-05-1, ISSN 1726-9687, Vienna, Austria.

[4] Fasth-Berglund, A. \& Stahre, J. (2013). Cognitive automation strategy for reconfigurable and sustainable assembly systems, Assembly Automation, Vol. 33 (3), page numbers (294-303).

[5] Fasth-Berglund, Å.; Palmkvist, F.; Nyqvist, P.; Ekered, S. \& Åkerman, M. (2016). Evaluating cobots for final assembly in Procedia CIRP, Vol. 44 page numbers (175-180).

[6] Peshkin M.; C.E.E.; Edward, J.; Peshkin, M.A. \& Wannasuphoprasit, W. (1996). Cobots.

[7] Wannasuphoprasit, W.; Akella, P.; Peshkin, M. \& Colgate, J.E. (1998). Cobots: A novel material handling technology, in Proceedings of International Mechanical Engineering Congress and Exposition, Anaheim, ASME 98WA/MH-2.

[8] Grigorescu, S.; Vatau, S. \& Dobra, A. (2010). Dedicated robot-robot cooperation, Chapter 55 in DAAAM International Scientific Book 2010, pp. 633-644, B. Katalinic (Ed.), Published by DAAAM International, ISBN 9783-901509-74-2, ISSN 1726-9687, Vienna, Austria

[9] Djuric, A.M.; Urbanic, R. \& Rickli, J. (2016). A framework for collaborative robot (CoBot) integration in advanced manufacturing systems, SAE International Journal of Materials and Manufacturing, Vol. 9 (2016-01-0337), page numbers (457-464).

[10] Heilala, J. \& Voho, P. (2001). Modular reconfigurable flexible final assembly systems, Assembly Automation, Vol. 21 (1), page numbers $(20-30)$. 
[11] Peschl, M.; Roening, J. \& Link, N. (2012). Human integration in task-driven flexible manufacturing systems, Proceedings of the 23rd International DAAAM Symposium, Volume 23, No.1, ISSN 2304-1382 ISBN 978-3901509-91-9, CDROM version, Ed. B. Katalinic, Published by DAAAM International, Vienna, Austria.

[12] Kolberg, D. \& Zühlke, D. (2015). Lean automation enabled by industry 4.0 technologies, IFAC-PapersOnLine, Vol. 48 (3), page numbers (1870-1875).

[13] Dulchlnos, J. \& Massaro, P. (2005). The time is right for labs to embrace the principles of industrial automation, Drug World Discovery, Winter-Issue, Vol. 2006 page numbers (25-28).

[14] Sekoranja, B.; Basi'c, D.; Svaco, M.; Suligoj, F. \& Jerbi'c, B. (2014). Human-robot interaction based on use of capacitive sensors, 24th DAAAM International Symposium on Intelligent Manufacturing and Automation, Vol. 69 page numbers (464-468).

[15] Bernhardt, R.; Surdilovic, D.; Katschinski, V. \& Schröer, K. (2007). Flexible assembly systems through workplace sharing and time sharing human-machine cooperation - PISA, IFAC Proceedings Volumes, Vol. 40 (3), page numbers (247-251).

[16] Francalanza, E.; Borg, J. \& Constantinescu, C. (2014). Deriving a systematic approach to changeable manufacturing system design in Procedia CIRP, Vol. 17 page numbers (166-171).

[17] Wiendahl, H.-P.; ElMaraghy, H.A.; Nyhuis, P.; Zäh, M.F.; Wiendahl, H.-H.; Duffie, N., et al. (2007). Changeable manufacturing - classification, design and operation, CIRP Annals - Manufacturing Technology, Vol. 56 (2), page numbers $(783-809)$.

[18] Eekels, J. \& Roozenburg, N.F. (1991). A methodological comparison of the structures of scientific research and engineering design: their similarities and differences, Design Studies, Vol. 12 (4), page numbers (197-203).

[19] Politze, D.; Bathelt, J.; Reinhard, M.; Jufer, N. \& Kunz, A. (2010). Interfacing product development and factory planning-towards a unified life cycle management, in Proceedings of the 7 th International DAAAM Baltic Conference Industrial Engineering, Tallinn, Estonia.

[20] Chryssolouris, G.; Mavrikios, D. \& Mourtzis, D. (2013). Manufacturing systems: skills \& competencies for the future, in Procedia CIRP, Vol. 7 page numbers (17-24).

[21] Hu, S.J.; Ko, J.; Weyand, L.; ElMaraghy, H.; Lien, T.; Koren, Y.; et al. (2011). Assembly system design and operations for product variety, in CIRP Annals-Manufacturing Technology, Vol. 60 (2), page numbers (715-733).

[22] ElMaraghy, W. \& Urbanic, R. (2004). Assessment of manufacturing operational complexity, in CIRP AnnalsManufacturing Technology, Vol. 53 (1), page numbers (401-406).

[23] Samy, S. \& ElMaraghy, H. (2010). A model for measuring products assembly complexity, International Journal of Computer Integrated Manufacturing, Vol. 23 (11), page numbers (1015-1027).

[24] Samy, S. \& ElMaraghy, H. (2012). Complexity mapping of the product and assembly system, Assembly Automation, Vol. 32 (2), page numbers (135-151).

[25] Nyhuis, P.; Heinen, T. \& Brieke, M. (2007). Adequate and economic factory transformability and the effects on logistical performance, International Journal of Flexible Manufacturing Systems, Vol. 19 (3), page numbers (286307).

[26] Chatterjee, P.; Athawale, V.M. \& Chakraborty, S. (2010). Selection of industrial robots using compromise ranking and outranking methods, Robotics and Computer-Integrated Manufacturing, Vol. 26 (5), page numbers (483-489).

[27] Ic, Y.T.; Yurdakul, M. \& Dengiz, B. (2013). Development of a decision support system for robot selection, Robotics and Computer-Integrated Manufacturing, Vol. 29 (4), page numbers (142-157).

[28] Mortensen, N.H. \& Hansen, C.T. (1999). Structuring as a basis for product modelling. Crit. Entusiasm, Trondheim: Tapir, page numbers (111-128).

[29] Krüger, J.; Lien, T.K. \& Verl, A. (2009). Cooperation of human and machines in assembly lines, in CIRP AnnalsManufacturing Technology, Vol. 58 (2), page numbers (628-646).

[30] Zühlke, D. (2009). SmartFactory- a vision becomes reality, IFAC Proceedings Volumes, Vol. 42 (4), page numbers (31-39).

[31] Rosati, G.; Faccio, M.; Carli, A. \& Rossi, A. (2013). Fully flexible assembly systems (F-FAS): a new concept in flexible automation, Assembly Automation, Vol. 33 (1), page numbers (8-21).

[32] Kittmann, R.; Fröhlich, T.; Schäfer, J.; Reiser, U.; Weißhardt, F. \& Haug, A. (2015). Let me introduce myself: I am Care-o-bot 4, a gentleman robot, Mensch Und Computer 2015-Proceedings.

[33] Hancock, P.A.; Jagacinski, R.J.; Parasuraman, R.; Wickens, C.D.; Wilson, G.F. \& Kaber, D.B. (2013). Humanautomation interaction research past, present, and future, Ergonomics in Design: The Quarterly of Human Factors Applications, Vol. 21 (2), page numbers (9-14).

[34] Maurice, P.; Padois, V.; Measson, Y. \& Bidaud, P. (2017). Human-oriented design of collaborative robots, International Journal of Industrial Ergonomics, Vol. 57 page numbers (88-102).

[35] Guiochet, J.; Machin, M. \& Waeselynck, H. (2017). Safety-critical advanced robots: a survey, Robotics and Autonomous Systems. 